Journal of Education and Educational Development

7(2), 269-285, 2020

DOI: http://dx.doi.org/10.22555/joeed.v7i2.27

\title{
The Perceptions and Practices of University Students and Teachers about Classroom Presentations
}

\author{
Kamal Uddin \\ kamal@kiu.edu.pk \\ Karakorum International University, Pakistan \\ Sadruddin Bahadur Qutoshi \\ sadruddin.qutoshi@kiu.edu.pk \\ Karakorum International University, Pakistan \\ Haji Karim Khan \\ hajikarim.khan@gmail.com \\ University of Baltistan Skardu, Pakistan
}

\begin{abstract}
Students' classroom presentations as teaching and assessment techniques are widely in practice at universities all over the world. Previous studies indicate that university students are provided unsatisfactory time for presentations. It frustrates them especially when teachers use the presentation as an assessment tool. The present study aimed to explore the views of teachers and students' perceptions behind their dissatisfaction with the uses of presentations by teachers as a teaching method as well as an assessment tool. In this qualitative study, researchers used semi-structured interviews from $14 \mathrm{M}$. Phil students and three of their teachers. Both teachers' and students' practices were also observed during sessions as scheduled for presentation activity. The observations were made towards the end semester from the qualitative thematic analysis. It was found that students' and teachers' expectations from each other regarding many aspects of the presentation did not match. Especially, students felt unhappy about the time duration allowed to prepare presentations. Feedback was also regarded as useless and of low quality. Presentations were more frequently used at the end of the semester rather than
\end{abstract}


through the semester. Teachers need to share criteria based on the possible time for an average student to understand and present the assigned tasks in class.

Keywords: assessment, higher education, learning, presentations, teaching strategy

\section{Introduction}

Presentation skills are important for postgraduate students in terms of their academic self-efficacy enhancing academic learning (Kukul \& Karatas, 2019). In addition, it has a long-lasting impact on their professional life even after the completion of their formal education (Nadeem et al., 2013). The authors further stated that the benchmark statements of all higher education courses emphasized that the university students must be able to impart information orally as well as in writings. Students consider presentation as an opportunity to confirm their learning by getting feedback from their teachers. However, it depends upon the university teachers in what ways they engage the graduates in such kinds of learning opportunities and what is the level and quality of the feedback that they provide to their students. Regarding feedback sheet and Tellison (2007) have indicated three sources of feedback: Teachers' feedback, peers' feedback, and self-reflection on recorded presentations. As compared to teacher's feedback, peer feedback was more appreciated as being a more effective approach to improve presentations (Grez, et al., 2012; Iksan, et al., 2012). However, in the context of this study, it was revealed that a formal way of peer feedback seemed missing. Whereas, presentation as a teaching method can be better used to generate peer feedback at the classroom level, depending on how teachers create such an opportunity for students to learn from each other.

Presentation is a complex activity in two ways: (1) it involves many verbal and nonverbal activities and (2) it has many different roles in an academic setting such as assessing students for their academic understanding, confidence building, and improving the language. Mostly, language plays a central role in communication while working with presentations (Grez, et al., 2012; Iksan, et al., 2012). One more aspect that makes presentations more complex is the individual differences that can challenge the management skills of both teachers and students (Nouri, \& Shahid, 2005). Miles (1999) asserted that personality differences are one 
reason that shapes the way people communicate during presentations. Miles (1999) found in a case study that students "overwhelmingly view presentation classes as an opportunity to improve their English language ability rather than learn how to give presentations" (p. 103).

Though in academic settings presentations are frequently used, we cannot claim that by just making presentations $p$ one can make any difference in learning. It is desirable to know what is presented and how it is presented; what are the requirements for a presentation to be meaningful and how presentation can contribute to students' learning. Thus, to answer these questions, we need to know how presentations are perceived and presented by students and how teachers use and assess their classes.

\section{Literature Review}

There are different expectations held by teachers and students about the use of presentations for overall learning and the learning of communication skills (Griffith Institute for Education, 2004). Griffith Institute for Education (2004) reported a student' views, on why universities overwhelmingly emphasize formal presentations, although most of the oral communication used in employment was based on round-table discussions. The teacher's response was: "I get them to describe their assignments. I ask them, "Here is a whiteboard; here is a pen. Tell me what you did" (p. 7). The above comments of the teacher and the student show a contrast in their expectations from the way presentation is used in classrooms. Such differences also lessen the effectiveness of the presentations. When we looked at the research findings from the Pakistani context, we found that "The current instructional scenario in our higher educational institutes is still replete with lots of instances of the traditional way of teaching with passive role of students who are not shown any quality models following which they can improve upon their skills such as presentation skills, problem-solving skills, effective leadership qualities, and other models of oral proficiency skills" (Nadeem \& Rahman, 2013, p. 223).

There are many other studies with similar findings indicating that the quality of teaching is not improving in the country (Ghori, 2019). Teaching methodologies are the key factors contributing to the learning of students. The presentation as being one of the best teaching strategies can replace the traditional 
way of teaching if properly managed and presented (Nouri \& Shahid, 2005).

The presentation as a teaching strategy needs to be understood well before it is applied in a classroom. According to Merriam-Webster's (2019), online dictionary, presentation is an activity in which someone shows, describes, or explains something to a group of people. In academic settings we can define it as: it is an activity in which a student presenter has ideas, knowledge, and attitudes to show, explain to some audience, usually to their classmates and teachers. However, the modes and ways of presentations can vary as per the situation (Griffith Institute for Education, 2004).

Students' presentations depend on the overall quality of their learning, level of confidence, and communication skills. Ramsden (1992) explained that the quality of learning depends on the approaches adopted by the students towards learning. These approaches include (1) deep approaches to learning and (2) surface approaches. He further indicated that whatever the approach students take depends on the educational environment. When he says students' learning approaches he means that the approaches are not what are in the minds of the students but they are related to how students experience learning (Rasool, 2010). Most of their approaches based on their intentions to meet the requirements of the teachers to get maximum marks in that presentation. Such learning experiences provide a context for them to generate their approaches toward learning.

Such a background demands that teachers are fully aware of the perceptions of their students to provide them feedback and help them manage their presentational and communication skills for a deep level of learning. Communication skills include the mix of verbal, interpersonal, and physical strategies needed to interact confidently and effectively with a range of audiences through the use of different audiovisual aids (Nouri \& Shahid, 2005).

Owen (2006) stated that motor skills in communication have become the foundation for interpersonal skills. The use of body language for communication was the primitive stage towards interpersonal communication. The author has cited Phillip (1978) according to whom a person is socially skilled if he can communicate with others, in the manners that fulfill one's right, requirements, satisfactions, or obligations to a reasonable degree without damaging the other 
person's similar rights, satisfactions or obligation and hopefully shares these rights (Iksan et al., 2012).

Feedback from the receivers is considered an important element in successful communications. Sheets and Tellson (2007) suggested many good points to make and manage presentations in a better way. These are as follows:

- College level communication courses can help all students to improve their presentations.

- Classroom communication behaviors influence students' communication skills thus, presentations also, university teachers have to be aware of them.

- Clear expectations from the side of faculty are essential about the format, context, and delivery and the use of the language of the presentation.

Iksan et al., (2012) have found that students mostly focus on language during presentation no matter what other objectives are in the mind of the teachers. Nouri and Shahid, (2005) reported that students rate three things as important for a good presentation. These factors are clarity of speech, correct language, and audience appeal. Grez et al., (2012) asserted that the assessment of oral presentations is an under-explored area. Normally, teachers assess students, but the above researchers have found that the self-assessment score of students is far better than teachers' assessment scores. Self-regulated learning has relations and encourages self- assessment practices. Since presentations necessarily have to serve different purposes. Thus, one key purpose should be to improve the communication skills of the students.

The Griffith Institute for Education's (2004) study has shown that a certain number of graduate students see no importance of the repetitive use of presentation in an artificial setting such as in the classroom; they think that they can improve by practically facing the presentation in real settings. Another study by Nouri and Shahid, (2005) recognized that the use of multimedia in the teaching-learning process is increasing globally. Similarly, Marckovic et al. (2012) have recognized the significance of the use of multimedia presentation designs in the teaching and learning process; however, the quality of multimedia material needs to be evaluated 
before its use. They have suggested that the problem of quality can be overcome by using standardized instruments to measure the quality of the material.

The use of technology is often involved in the presentation, however, technology is not without problems. For example, the use of technology is likely to divert attention to other directions than the actual content which is taught through technology such as multimedia. It necessitates that such areas should be explored where the true value of technology could be elaborated. Few studies have covered actual classroom practices regarding presentations as a strategy for overall learning. Thus, this study may be expected to help in understanding the actual practices and problems related to the effective use of students' presentations in classrooms of higher education levels.

\section{Methodology}

Exploring perceptions of university teachers about their use of classroom presentations as a tool for learning and assessment was investigated through qualitative case study design. The qualitative data were obtained using semi-structured interviews and classroom observations. The semi-structured interviews took the views of students of M.Phil level class in the education department of the selected university. All the students enrolled were involved in interview discussions. Later on, classes were observed during sessions, which scheduled the regular presentations for assessment purposes. The result of this investigation was an in-depth understanding of classroom presentations as viewed and practiced by students and teachers in context.

\section{Sample}

In this study, a whole class of 14 MS level students and three teachers teaching the same class were included as study participants. Both teachers and the students were requested to participate in the study by giving interviews. They were from a teacher education program of the Department of Education is one of the public sector universities in Gilgit-Baltistan. In total 14 students were enrolled and three teachers were teaching the same class of M. Phil while this study was being conducted. All the teachers were male with Ph.D. qualification with teaching experiences between five to 10 years. 13 out of 14 samples of students were female with only one male. 


\section{Instruments}

In qualitative case studies interviews, formal discussions, observations, and document reviews are considered powerful tools of data collection to make meaning of the study (Creswell, 2012). However, for this study, semi-structured interviews were used for data collection. The aim was to explore students' and teachers' understanding and experiences on the way they used presentations as a teaching method and as a tool for assessment and the related challenges. Researchers used semi-structured because we expected that in a fully structured interview we might not be able to explore the responses that could arise based on the participant's own understanding and situation. The second tool also used semi-structured observations for the same reason to adjust with important information that would arise out of the actual situation in the field. The features of the observation were:

1. It was a non-participant observation because, in the classes of M. Phil program, the researchers needed to know what the group under observation was doing about presentation.

2. Each class of M. Phil was observed twice (during class session) by two members of our research team, both qualified $\mathrm{PhDs}$ in the field of education.

3. The observation schedule contained indicators similar to research questions asked in the interview, e.g., the first indicator was 'What content of the presentation was under discussion in class and how it was being discussed?'

The interviews were conducted before the observations to ensure the validity of the data being collected, which also helped to know how participants' views related to their actual practice in the context. Interviews took 20 to 30 minutes given the high number of participants in our case. The interview questions included, for instance, 'How effectively your teachers manage presentations for your learning?'. Similar questions, with slight modifications, were used to get information from the three selected teachers.

\section{Data Analysis}

Researchers developed open-ended questions for an interview of 20-30 
minutes per interview. The interviews were taken in Urdu, however, for reported purposes they were translated soon after the interviews. Observation schedules in line with the interview discussion were developed. Field notes from observations were used for writing down the details of what happened during classroom presentations. The objectives of the study were the 'signposts' that provided the researchers with a direction for the analysis of the field notes (Cresswell, 2012). Different themes came to the surface from reading and comparing different categories of information in the field notes text. The next was the coding processes for developing themes based on the codes, and different categories emerged from the data. The data were analyzed qualitatively by grouping different categories of data into emerging themes. These themes are reported in descriptive form. Interview findings in the form of different themes were discussed which were then triangulated with observational findings. Some direct statements were quoted to ensure the originality of the findings. Further detailed discussions concerning the research questions were made in the findings section. The participants' actual names were not revealed, rather pseudonyms were used so that confidentiality should be ensured, which is an important aspect of any research ethics that involves human sample.

\section{Findings and Discussion}

\section{Students Perceptions about the Purposes of Presentations}

Two main purposes of using presentations emerging from the study can be described in two sub-themes: a) covering the syllabus with the help of presentations, and $b$ ) the use of presentations to assess students at the end of the semester. The teachers of the purposes and how presentations would be conducted did not inform the students. However, this was a perceived view of students who were presenting topics in their class as an assignment:

"Teachers use presentation at the end of the semester for assessment purposes. Few presentations happen in advance. Teachers use lectures mostly when they are unable to finish the course, they ask students to give presentations on different topics." 
Another participant expressed her views in these words:

"Though teachers never mentioned... for what purpose they take presentations. It seems that they take the presentation to cover syllabus because the students work on the topics they are assigned."

Previous studies report the similar type of findings, for example, Rasool (2010) reported that one of the reasons for poor quality teaching at higher education in Pakistan is teachers' lack of interest in involvement with the students' learning. Besides, lecture-based teaching is still prevalent and has no impact on students' creative learning (Din, 2015; Ghori, 2019; Mahboob, 2017). Other reasons could be teachers' perceptions about their role as teachers, and students' motivation level as reported in many other studies (Amjad \& Inamullah, 2014; Rasool, 2010).

\section{Criteria of Presentation}

A question was directed to know whether the teachers shared any criteria about class presentations and if so, what criteria were shared. All the participants responded that there were no criteria shared by the teachers in advance. One of the participants said:

"There are no clear criteria. She added, 'Teachers do not share any criteria for presentations. We were not clear what teachers were supposed to assess and what we were supposed to present."

However, another participant stated some points, which seemed to have implicit criteria shared by one or two teachers within the sample, as commented by an M. Phil student.

"There are no criteria discussed earlier or later during classes. Yes, one of my teachers does inform about the time duration for one presentation but even the time is not strictly followed. Some students are allowed to speak more than others especially talkative students who take more time. One more thing I remember is that eye contact is also encouraged during presentations."

From her response, it seemed that the teacher/s shared criteria were not 
well-elaborated to some extent even if it was of minor importance, such as time duration for presentation and eye contact. This could be a simple criterion that teachers could have shared with their students but the participant did not even realize that criterion. When she has posed a counter-question whether she did not think that the 'time duration' and 'eye contact' were the criterion, she replied that even if it was important, the teachers did not emphasize any one criterion-it was not written, nor do it they apply on all presenters. Regarding presentation assessment criteria, all other responses were similar in that there were no clear criteria.

This finding was consistent with the observational findings as the teachers allowed some students to take more time than others. This showed that teachers used students' presentations for teaching as well as for assessment purposes; however, they did not appear to be developing clear criteria in the form of rubrics that could explain what to present, how to present, and why to present. In addition to not providing some clear guidelines about time duration, there was no appropriate use of eye contact, asking questions from the class, and seeking their views for further improvement in their presentations (Abbas et al., 2019/in press). Studies indicate that students' performance is affected by teachers' approach towards teaching and learning (Ghazal, et al., 2014; Gruber, 2010; Khan, 2013; Ramsden, 1972).

\section{The Nature and Quality of Feedback in Presentation}

Two questions were asked aiming at eliciting information regarding the effectiveness of teachers' feedback on presentations. Participant 2 said that teachers appreciated her efforts to present the topic in the class. To the same respondent, a probing question was asked about her satisfaction with the feedback provided by the teachers. She replied:

\section{"Only 40 percent satisfied'.}

Other respondents also quantified their satisfaction ranging from 20 to 50 percent for teachers' feedback. Similarly, Participant 3 shared her point of views as:

"The teachers hardly provided any feedback. At times they just added some information as an additional discussion without telling what the presentation should contain and how it should be presented." 
Another respondent shared:

"They (the teachers) just added more information on what I just said. They never provided feedback in a systematic way such as using rubrics and identify week areas."

The participants, overall, seemed dissatisfied with the feedback provided by the teachers. They expressed that their teachers did not provide feedback, as they wanted. Regarding peer feedback, the participants reported that the class did not have such a culture where peer feedback is given. However, only one participant stated that two or three of her class fellows not only provided feedback to her but also helped her in her studies more than the teachers did. This revealed that the students received very general feedback from teachers on the presentation. The quality of feedback appeared to be very low and students did not get any benefit from the feedback from the teacher in terms of their learning and guidelines for further improvement in their future presentations. Thus, teachers needed to provide specific and constructive feedback to the students on their presentations.

Constructive feedback from teachers can not only add value to the presentation as an approach to teaching but also enable the presenters to find their weaker areas for improvement with a certain level of grading in the presentations. Teachers' constructive feedback at all levels is reported to be of high importance for students' learning (Din, 2015; Khan, 2013, Qutoshi, 2016; Ramsden 1972). The teacher seemed to be unaware of what feedback they should provide if they had to at all. They seemed to lack information about the needs of the learners even though literature shows the positive impact of teacher feedback on students' learning (Sheet et al., 2007).

\section{Teachers' Communication Skills}

The quality of teacher talk also emerged as an issue. It was considered an important factor that highly contributed positively or negatively to students' overall learning as well as their communication skills in the presentation. Thus, some questions were asked to know what the students perceived the quality of their teachers' communication skills. They responded: 
"Majority of teachers' communication is poor. They do not use English in classes except for one teacher. Some of the teachers spoke louder than the required volume, some use confusing words by which no concept can be properly understood."

This shows that teacher had low communication skills (in English, as expected by the students) though all were PhDs. The responses of the participant-6 were also consistent with the observation. During observations, it was found that teachers used the local language (Urdu) while discussing students' presentations. Students had prepared their PowerPoint presentations on the slides written in English while they were presenting in the Urdu language. They were even sharing irrelevant examples sometimes, which teachers often avoided commenting on.

Fewer studies from the Pakistani context show teacher-student communication practices at the university level; however, quality of teaching is not satisfactory as reported by many authors (Din, 2015; Khan; 2013).

\section{Students' Difficulties in Performing Presentation}

Another question was asked to illicit problems faced by the participants while conducting a presentation as a classroom activity. It was found that teacher feedback was not available to them in time, which was a great challenge for students to improve their presentations for the next time. A participant, for example, mentioned:

"To me, it is a time-consuming activity. It causes wastage of time for the students who are listeners because we can't understand the presentation of our class fellows as the information provided by them is not clear while teachers do not critically examine the content and method of presentations."

Another participant shared her views saying:

"It was not much fruitful because the topics were trivial, we had covered these courses at a master level which are being offered again thus we have to repeat almost the same content." 
Participant 10 stated:

"There was no focus on one single point, usually student presentations lead to irrelevant discussions, the teacher had no idea over the control of the class discussion, besides the discussion consisted involving many irrelevant scattered points."

Participant 3 shared views in such words:

"Presentations were ineffective because they were not properly managed and no proper feedback was provided after presentations. She further stated that students were being asked to present at the end of the semester while we are busy covering different course assignment, we cannot concentrate on all at the same time. The entire participant indicated the "mismanagement of presentations."

During the observation, it was noted that teachers were more concerned with their paperwork while students were presenting. The presentations were carried out for summative assessment of the students while it should have been a great opportunity for learning for a class like M. Phil. Students' motivation and enthusiasm level on their presentation work was also a bit lacking in terms of their interest in terms of learning; rather, they were 'marks conscious'. Literature from the Pakistani context reported enough complaints and problems regarding the traditional way of assessing students and faculty mechanism of learning (Grez, et al, 2012; Iksan, et al., 2012; Mehaboob, 2019; Rasool, 2010).

\section{Role of Peer Feedback}

One of the participants was emphasizing how her classmates helped in developing and designing her presentations. She said:

"Teachers never bothered to highlight what I was lacking in presentation, how I designed it, and what is lacking in my oral performance during the presentation. The teachers silently sit in the back of the class holding a pen and listening to whatever I said and when I was done the next presenter was asked to present. I think the teacher judged my performance even without telling how he judged my performance." 
For further clarity, another participant's response was taken. She was asked a probing question: 'What was the source of feedback for improving her presentation?' She said that one of her class fellows helped in not only improving her language but also helped her in reformatting her presentation. From these responses, it was evident that peer feedback was a very useful area that a teacher could attend to in class (Grez et al., 2012). One of the teachers asked the class during observation to give their input on how the presenter did. They all highlighted both shortcomings and appreciable points of the presenter.

Their peers better judged their performance than their teachers did. The participants, therefore, found peer feedback as a better alternative to the teachers' feedback. There seemed to be some negative impact of peer feedback, which was that the comments from the peer-influenced teachers' perceptions of the student's performance because the presentation was being taken for grading purposes by the teacher. No studies are showing reliable results on both the advantages and disadvantages of peer-feedback (Nadeem et al., 2013). From this study, however, it seemed that at M. Phil level peer feedback was a great contributor to students' learning even more than teacher feedback.

\section{Cultural Differences between Students and Teachers}

Although it was not clear enough from interviews, it came to be noticed during the observations that the teachers who were from a different culture tended to have less communication with the students. Students' preferred to talk in their local language even within the class. The teachers avoided taking notice of what they were talking about. Such teachers avoided commenting on what students said and thought about the topics of their presentations. It seemed that such teachers' attitude was not friendly and warm with the learners. The researchers came to realize that there existed a non-conducive environment in class, i.e., an air of artificiality in teacher and student interaction during observations.

Literature in the Pakistani context does not say much on the issues related to the difference between the students and teachers in terms of their cultural and linguistic background. There seems to be a lack of research in this particular area, as identified in this study. However, in general, some studies report that the closer the teachers are with the students' routine experience, the more effective their 
teaching be omes(Amjad \& Inamullah, 2014; Grez, et al., 2012; Iksan et al., 2012; Sheet et al., 2007).

\section{Conclusion and Recommendations}

From the findings and the discussions concerning literature from Pakistani context and across the world, what the authors learned was that presentations had a great role in enhancing communication skills in general, especially because it provides students sufficient opportunities to practice. As per the perceptions of the students, it was a source of generating feedback for their learning. , However, this aspect was missing. Peer feedback was an obvious contributing factor in their learning, though teachers had no clear guidelines on providing feedback. The students did not get enough time to prepare their presentations, nor did they have clear criteria on how to present their topics and demonstrate the basic purpose of those presentations.

Some of the following factors related to the use and quality of presentation were identified: poor quality of teaching (e.g., just deliver lecture without having close interactions with students to engage in their learning); improper time management for presentations; lack of feedback; unclear purpose and criteria for presentation; lack of the culture of using peer feedback as an alternative to teacher feedback; unsatisfactory time management; and, the use of presentations with unclear purposes.

Based on these factors it is recommended that university teachers need awareness sessions not only on the role of feedback but also on how they need to provide feedback. Developing clear criteria before asking students to present their work is highly desired by the students, thus it could be a useful strategy to make the most from the presentations activity. Presentations should not only be used for grading but also be recognized and adopted as a teaching and learning strategy to maximize benefits especially in M.Phil and Ph.D. level classes with clear guidelines by providing scheduled presentations throughout the course work plan. 


\section{References}

Amjad \& Inamullah M. (2014). Perception of teacher educators regarding teacher education program in KPK Pakistan. Bulletin of Education and Research, $36(2), 1-12$.

Andeweg, B. A., Laaken, B. M. D., \& Swenen, M. A. (2014). Watch yourself: Giving feedback on recorded presentations in virtual learning. Institute for Technology and Communication, Delft University of Jafflan. https://www.yumpu.com/en/document/view/26202992/watch-yourself-givi ng-feedback-on-recorded-presentations-sefi

Din, U. K. (2015). Teachers' perceptions on the role of English in students' assessment at higher education. International Journal of Social Science Studies, 3(3), 138-148.

Ghazal, L., Gul, R., Hanzala, M., Jessop, T. \& Tharani, A. (2014). Graduate students' perception of written feedback at a private university in Pakistan. International Journal of Higher Education, 3(2), 13-27. https://eric.ed.gov/?q=students+perception+about+teacher+feedback

Ghori, S., (January 13, 2019). Higher Education in Pakistan: Time to listen to the students. Daily Times.

https://dailytimes.com.pk/343493/higher-education-in-pakistan-time-to-lis ten-to-the-students/

De Grez, L., Valcke, M., \& Roozen, I. (2012). How effective are self-and peer assessment of oral presentation skills compared with teachers' assessments?. Active Learning in Higher Education, 13(2), 129-142.

Griffith Institute for Education. (2004). Oral communication tool kit. Griffith University Australia.

Gruber, T. (2010). Examining student satisfaction with in higher education services: Using a new measurement tool. International Journal of Public Sector Management, 23(2), 105-123.

Iksan, Z. H., Zakaria, E., Meerah, T. S. M.,, Osman, K., Lian, D. K. C., Mahmud, N., D., \& Krish, P. (2012). Communication skills among university students. Procedia-Social and Behavioral Sciences, 59, 71-76.

Kukul V., \& Karatas, S. (2019). Computational thinking self-efficacy scale: Development, validity and reliability. Information in Education, 18(1), 151-164.

Khan, H. I. (2013). An investigation of two universities' postgraduate students and their teachers' perceptions of policy and practice of English medium of 
instruction (EMI) in Pakistani universities (Doctoral dissertation). http://theses.gla.ac.uk/4451/

Marckovic, M. G., Pogaraci, I. M., \& Mezak, J. (2012). Role and importance of presentation design in learning and in quality of multimedia learning material. www.wseas.org/multimedia/books/2012/Porto/EDUTE.pdf

Merriam, S. B. (1998). Qualitative research and case study applications in education. Jossey-Bass.

Miles, R. (1999). Oral presentations for English proficiency purposes. Reflection on English Language Teaching, 8(2), 103-110.

Nadeem, M., \& Rahman, A. (2013). Tackling oral communication skills' enigma through presentation at higher education. Asian Journal of Social Sciences and Humanities, 2(3), 222-229.

Nadeem, Asif, \& Tahir (2013). Exploring impact of teachers' feedback on learner's learning behavior at university level, Journal of Educational Research, 16(2), 54-62.

Nouri, H., \& Shahid, A. (2005). The effect of PowerPoint presentations on student learning and attitudes. Global Perspectives on Accounting Education, 2, 53.

Owen, H. (2006). The handbook of Communication skills. Routledge.

Qutoshi, S. B. (2016). Ruminating, assessment practices. In S. B. Qutushi (2016), Creating living educational theory: A journey towards transformative teacher education in Pakistan (pp.249-300).

https://www.actionresearch.net/living/sadrudding.shtml

Ramsden. (1992). Learning to teach in higher education. London: Rutledge.

Rasool, S. (2010). A comparative study of the quality assurance practices in public and private universities (Doctoral Dissertation). University of the Punjab. http://prr.hec.gov.pk/jspui/handle/123456789/1021

Sheets, B. H., \& Tellson, L. (2007). Strategies for improving students 'presentation skills. http://www.westga.edu/ bquest/2007/presentation7.pdf

\section{Citation of this Article:}

Uddin, K., Qutoshi, S. B., \& Khan, H. K. (2020). The perceptions and practices of university students and teachers about classroom presentations. Journal of Education and Educational Development. 7(2), 269-285. 